\title{
Establishment and quality evaluation of a glioma biobank in Beijing Tiantan Hospital
}

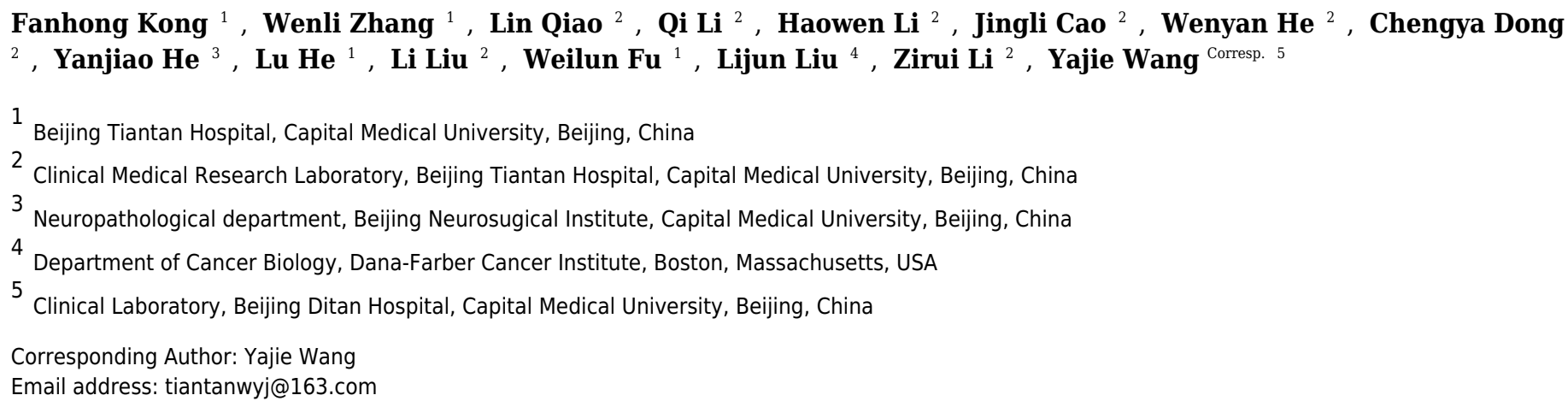

Background: We established a glioma biobank at Beijing Tiantan Hospital in November, 2010. Specialized residents have been trained to collect, store and manage the biobank in accordance with standard operating procedures.

Methods: One hundred samples were selected to evaluate the quality of glioma samples stored in the liquid nitrogen tank during different periods (from 2011 to 2015) by morphological examination, RNA integrity determination, DNA integrity determination and housekeeping gene expression determination.

Results: The majority of samples (95\%) had high RNA quality for further analysis with RIN $\geq 6$. Quality of DNA of all samples were stable without significant degradation.

Conclusion: Storage conditions of our biobank are suitable for long-term (at least 5 years) sample preservation with high molecular quality. 
1 Establishment and quality evaluation of a glioma biobank in Beijing Tiantan Hospital

\section{Abstract :}

Background: We established a glioma biobank at Beijing Tiantan Hospital in November, 2010. Specialized residents have been trained to collect, store and manage the biobank in accordance with standard operating procedures.

Methods: One hundred samples were selected to evaluate the quality of glioma samples stored in the liquid nitrogen tank during different periods (from 2011 to 2015) by morphological examination, RNA integrity determination, DNA integrity determination and housekeeping gene expression determination.

Results: The majority of samples $(95 \%)$ had high RNA quality for further analysis with RIN $\geq 6$. Quality of DNA of all samples were stable without significant degradation.

Conclusion: Storage conditions of our biobank are suitable for long-term (at least 5 years) 
sample preservation with high molecular quality.

\section{Introduction}

Gliomas refer to a group of tumors that arise from the glial tissue of the central nervous system. Basically, they can occur anywhere in the central nervous system, both brain and spine. Gliomas are the most commonly occurring tumors of the central nervous system which make up about $27 \%$ of all brain tumors and $80 \%$ of all malignant primary brain tumors (Agnihotri et al.,2013; Wilson, Karajannis\&Harter,2014; Aldape et al.,2015). The incidence rate of glioma is approximately 4.67-5.73 per 100000 persons (Ostrom et al.,2014). Glioblastoma (GBM) is the most malignant type of gliomas. The median survival time of patients with GBM is $12-15$ months (Bryukhovetskiy et al.,2016).

Tumor biobanks aim to systematically collect, store, manage and utilize tumor tissues from surgical removal, blood samples and also the corresponding participant data for further use of scientific projects and more specifically, for clinical and translational research (Watson, Kay\&Smith,2010; Kang et al.,2013). Relying on the neurosurgery discipline, a well-managed and normative glioma biobank was established in our hospital in November, 2010. Using morphological examination, RNA integrity determination, DNA integrity determination and housekeeping gene expression determination, the quality of the glioma tissues stored in the liquid nitrogen tank for 1-6 years (collected from 2011 to 2015) was evaluated in order to provide high quality samples for medical research.

\section{Materials and methods}

\section{Laboratory equipment}

The lab is equipped with $-80^{\circ} \mathrm{C}$ freezers, $-150^{\circ} \mathrm{C}$ freezers and liquid nitrogen tanks. Each freezer has a specialized temperature monitoring system to detect real-time temperature. When the temperature inside freezers is abnormal, alarm messages will be sent to biobank managers. Central air-conditioning system keeps the room temperature around $20^{\circ} \mathrm{C}$.

\section{Collection and storage of tumor tissues}


54 Excised glioma tissues from patients were collected immediately by trained and experienced 55 staffs as soon as tumor samples were removed from the body during neurosurgery. Consent to use 56 resected tissues was obtained from all cancer patients prior to surgery. This study was approved 57 by the Ethics Committee of Beijing Tiantan Hospital ( KY2014-021-02). Fresh human glioma 58 tissues were obtained directly after surgery was completed. . Blood and necrotic tissue on the surface of the samples were washed off with pre-cooling PBS. Then the tumor samples were cut into small pieces (about $0.5 \mathrm{~cm} \times 0.5 \mathrm{~cm}$, thickness $<0.5 \mathrm{~cm}$ ) under aseptic conditions, repackaged in cryotubes and quickly frozen in liquid nitrogen tank in the operating room for temporary storage. All samples were frozen within $30 \mathrm{~min}$ after resection (Tonje et al.,2016). On the same day, they were transferred to liquid nitrogen tanks in the biobank for long-term preservation. Registration of samples were done at the same time. Clinical information of patients including name, gender, age, pathological diagnosis, clinical diagnosis and treatment were all recorded and stored in the database.

\section{Morphology characteristics}

One hundred samples were selected to conduct the following experiments from 2011 to 2015 .

For each year, twenty samples were selected randomly. Firstly, the tissue fragments were fixed in $10 \%$ formalin before thawed for 24 hours then embedded in paraffin. Next, five-micrometer tissue sections were cut, dewaxed and stained with Hematoxylin-Eosin (HE) in accordance with standard procedures (Iigen et al.,2014). The slides were observed by an experienced pathologist. Tumor samples which were comprised of $\geq 80 \%$ tumor nuclei and $\leq 20 \%$ necrosis $(\leq 50 \%$ necrosis for GBM) were considered fit for other research.

\section{RNA isolation}

Total RNA was isolated using TRIZOL reagent (Invitrogen, Stockholm, Sweden). 1ml TRIZOL reagent was added into an RNAse-free tube. 100mg frozen tissue of each sample was then removed into the tube and homogenizated using RNAse-free pestles. The homogenizated tissue was incubated in TRIZOL reagent for 10 minutes at room temperature. After those, 200ul 
80 chloroform was added into each tube, and the tubes were manually shaken for 15 seconds before

81 placed at room temperature for 10 minutes. The tubes were centrifuged at 12,000rpm for 15

82 minutes at $4^{\circ} \mathrm{C}$, after which the aqueous phase was transferred to a new RNAse-free tube.

83 Afterwards, 500ul isopropyl alcohol was added into each tube and incubated at $-20^{\circ} \mathrm{C}$ for 20

84 minutes. The tubes were centrifuged at $12,000 \mathrm{rpm}$ for 10 minutes at $4^{\circ} \mathrm{C}$. The supernatant was

85 discarded, and $1 \mathrm{ml} \mathrm{75 \%}$ ethanol was added into each tube to wash RNA pellet. Finally, the tubes

86 were centrifuged at $7500 \mathrm{~g}$ for 10 minutes. The supernatant was discarded, and the RNA pellet

87 was air-dried and subsequently dissolved into 30ul RNase-free water.

\section{RNA yield and integrity determination}

A Nanodrop spectrophotometer (Thermo Fisher Scientific) was used to determine concentrations (ng/ul) and purity of RNA samples. The A260/A280 ratio was measured to indicate RNA purity. The ratio of samples with high purity is 1.8 2.1 (Sanabria et al.,2014). An Agilent 2100 bioanalyzer in conjunction with the RNA 6000 Nano and the RNA 6000 Pico LabChip kits Agilent Biotechnologies, Palo Alto, CA y was used to evaluate RNA integrity, from which RNA integrity number (RIN) was calculated. A scoring system between 1 and 10 were used in the RIN software, with 1 representing degraded RNA and 10 representing very highquality, intact RNA (Griffin et al.,2012). In literature, samples were divided into four quality groups according to RIN: RIN $<5$, not reliable for demanding downstream analysis; $5 \leq \mathrm{RIN}<6$, suitable for quantitative reverse transcription-PCR (RT-qPCR); $6 \leq \mathrm{RIN}<8$, suitable for gene array analysis; and RIN>8, suitable for all downstream techniques (Kap et al.,2014). The assays were performed according to the manufacturer's instructions.

\section{cDNA synthesis and real-time quantitative PCR (RT-qPCR) for housekeeping genes}

Extracted RNA (1ug) was reverse-transcribed to first-strand cDNA using the PrimeScript RT reagent Kit With gDNA Eraser (TaKaRa). Afterwards, 2ul cDNA solution was used for a 40cycle SYBR Green PCR assay with the SYBR Premix EX Taq reagent (TaKaRa). The same sample was run three different times in the same experiment to remove any outliers. Primer sets 
106

107

108

109

110

111

112

113

114

115

116

117

118

119

120

121

122

123

124

125

126

127

128

129

130

131

132

were as follows: human ACTB: forward primer 5'-TTAGTTGCGTTACACCCTTTCTTG -3'; reverse primer 5'- GTCACCTTCACCGTTCCAGTTTT-3'; human GAPDH: forward primer 5'CTATAAATTGAGCCCGCAGCC-3'; reverse primer 5'-GCGCCCAATACGACCAAATC-3', The Thermal Cycler DiceReal Time System (TaKaRa) was used for qRT-PCR under the following conditions: $95^{\circ} \mathrm{C}$ for $30 \mathrm{~s}, 95^{\circ} \mathrm{C}$ for $5 \mathrm{~s}, 58^{\circ} \mathrm{C}$ for $30 \mathrm{~s}, 72^{\circ} \mathrm{C}$ for $30 \mathrm{~s}$.

\section{DNA isolation}

$100 \mathrm{mg}$ frozen tissue of each sample was pulverized to isolate genome DNA. DNA isolation was accomplished using the EasyPure Genomic DNA kit (Transgen Biotech) according to the manufacturer's instructions. In the end, the DNA pallet was dissolved into 50ul ddwater(PH>8.0). DNA yield and PCR for housekeeping genes

A Nanodrop spectrophotometer (Thermo Fisher Scientific) was used to determine concentrations (ng/ul) and the A260/A280 of DNA samples. After that, 50ng genomic DNA was used for a 40cycle SYBR Green PCR assay with the SYBR Premix EX TaqII reagent (TaKaRa). Each measurement was performed in triplicate to remove any outliers. Primer sets were as follows: human ACTB: forward primer 5'-AAGACCTGTACGCCAACACA-3'; reverse primer 5'CTGGATGTGACAGCTCCCC-3'; the primer set of human GAPDH was the same as mentioned before.

\section{B-Globin PCR amplification}

Four different length fragments of the housekeeping gene $\beta$-globin were amplified to evaluate DNA quality(Le Page C et al.,2013,). The maximum amplicon size positively correlates with DNA quality. DNA samples were of good quality with at least three amplified ß-globin bands of increasing size(Le Page C et al.,2013,). PCR amplification was performed with $50 \mathrm{ng}$ of tissue DNA using DNA Polymerase High Fidelity (TransTaq). The primers are shown in Table 1. PCR was performed using the following conditions: primerI : initial denaturation at $94^{\circ} \mathrm{C}$ for $5 \mathrm{~min}$, followed by 35 cycles of denaturing at $94^{\circ} \mathrm{C}$ for $30 \mathrm{~s}$, annealing at $56^{\circ} \mathrm{C}$ for $30 \mathrm{~s}$, extension at $72^{\circ} \mathrm{C}$ for $30 \mathrm{~s}$, and final extension at $72^{\circ} \mathrm{C}$ for $5 \mathrm{~min}$; primerll = initial denaturation at $94^{\circ} \mathrm{C}$ for 5 min, followed by 35 cycles of denaturing at $94^{\circ} \mathrm{C}$ for $30 \mathrm{~s}$, annealing at $52^{\circ} \mathrm{C}$ for $30 \mathrm{~s}$, extension at 
$13372^{\circ} \mathrm{C}$ for $30 \mathrm{~s}$, and final extension at $72^{\circ} \mathrm{C}$ for $5 \mathrm{~min}$; primer III = initial denaturation at $94^{\circ} \mathrm{C}$ for

$1345 \mathrm{~min}$, followed by 35 cycles of denaturing at $94^{\circ} \mathrm{C}$ for $30 \mathrm{~s}$, annealing at $52^{\circ} \mathrm{C}$ for $30 \mathrm{~s}$, extension 135 at $72^{\circ} \mathrm{C}$ for $1 \mathrm{~min}$, and final extension at $72^{\circ} \mathrm{C}$ for $5 \mathrm{~min}$; primer IV = initial denaturation at $13694^{\circ} \mathrm{C}$ for $5 \mathrm{~min}$, followed by 35 cycles of denaturing at $94^{\circ} \mathrm{C}$ for $30 \mathrm{~s}$, annealing at $54^{\circ} \mathrm{C}$ for $30 \mathrm{~s}$,

137 extension at $72^{\circ} \mathrm{C}$ for $1 \mathrm{~min}$, and final extension at $72^{\circ} \mathrm{C}$ for $5 \mathrm{~min}$. PCR products were analyzed 138 on agarose gels.

\section{Statistical analysis}

140 Statistical differences were analyzed using one-way ANOVA test. The criterion for significance 141 was set at $P$ value $<0.05$.

\section{Results}

\section{Composition of the biobank}

144 The total number of cancer cases reached 3686 from 2010 to 2016. 3,686 patients were 145 consented and tissue was collected from each patient. Fig.1 showed the constituent ratio of 146 glioma subtypes. The vast majority subtypes of the biobank were oligo-astrocytoma, astrocytoma 147 and glioblastoma.

\section{Morphology characteristics}

149 According to the HE staining results, all tumor samples were comprised of $\geq 80 \%$ tumor 150 nuclei and $\leq 20 \%$ necrosis ( $\leq 50 \%$ necrosis for GBM). Fig.2 shows the representative images 151 from the 100 samples. No significant tissue decomposition was detected in all selected samples.

\section{RNA integrity of different storage duration}

153 The majority of RNA samples had a A260/A280 ratio ranging between 1.8 and 2.1 which 154 indicate high purity (Fig.3). The RIN results of the selected 100 samples showed that 95\% 155 samples in the biobank were suitable for RT-qPCR and gene array analysis with RIN $\geq 6$ ( Fig.4). 156 Besides, no significant change in the RNA quality was found among different storage periods 157 (from 2011 to 2015). 
158

159

160

161

162

163

\section{RT -qPCR for Housekeeping genes}

RT -qPCR for housekeeping genes (GAPDH, ACTB) was performed to verify the accuracy of RIN determination. Except for the 5\% samples with $\mathrm{RIN}<6$, of which the ct values were relatively higher, gene expression levels of all the other $95 \%$ samples remained stable under different storage periods (Table 2 and Fig.5). No significant difference was found.

\section{DNA integrity of different storage durations}

The A260/A280 and PCR for genomic housekeeping genes (GAPDH, ACTB) were performed to evaluate DNA degradation level. DNA samples had a A260/A280 ratio ranging between 1.8 and 2.0 with the exception of two samples showed ratios of 2.05 and 2.07 (Fig.6), suggesting contamination during the phenol extraction. According to the PCR results, all the ct values were stable of different storage durations, no significant difference was found (Fig.7). DNA quality was assessed also by PCR amplification of ß-globin gene fragments. The integrity of DNA was scored according to the number of amplified bands of increasing size from 1 to 4 . According to our results, $100 \%$ of extracted DNA samples were of good quality with at least three amplified B-globin bands of increasing size(Table 3). No significant difference was found in DNA quality of different storage durations.

\section{Discussion}

Tumor biobanks aim to collect and store sufficient number of tumor samples with high quality for basic cancer research .Clinical and basic researchers use these samples to carry out molecular biology, cell biology, genetics, transcriptomics, genomics and proteomics research in order to explore new standard of tumor classification, diagnosis, treatment and prognosis. Prolonged storage periods of tumor samples allows researchers to design studies to identify biomarkers of aggressiveness and responses to different drug treatments which increases their value (Hewitt,2011; Olivieri et al.,2014). Thus, establishment of tumor biobanks with high quality samples plays an important role in personal medicine and translational research.

Compared with other moleculers, the RNA molecule is less stable and more likely to degrade 
184 by RNases because its ribonucleotides contain a free hydroxyl group in the pentose ring (Zhang 185 et al.,2016). However, in our study, we didn't find significant RNA degradation in samples 186 preserved in the liquid nitrogen tank $\left(-196^{\circ} \mathrm{C}\right)$ for 1-6 years (from 2011 to 2015). Except for few 187 samples $(5 \%)$ with $\mathrm{RIN}<6$, the majority of them $(95 \%)$ remain high quality for further analysis 188 with RIN $\geq 6$. We verified the accuracy of RIN determination by RT-qPCR of housekeeping genes (GAPDH, ACTB). The number of cycles required to reach a detectable threshold level for fluorescence is defined as ct. Ct is inversely correlated with the amount of template RNA (Riemer et al.,2012). Thus, RNA samples with high quality have a relatively lower ct value whereas RNA samples with degradation have a relatively higher ct value of housekeeping genes. Our results of RT-qPCR were in accordance with RIN determination. All the 95\% samples with RIN $\geq 6$ have stable ct values of housekeeping genes (ACTB: $14.32 \pm 0.47 \cdots 14.70 \pm 0.65$; GAPDH: $21.11 \pm 0.75$ 22.17 \pm 1.01 ). Our findings were consistent with those of Andreasson et al. (2013), who assessed RIN values in endocrine tissues stored at $-80^{\circ} \mathrm{C}$ for approximately 30 years and found that long-term storage in $-80^{\circ} \mathrm{C}$ did not adversely affect the quality of the RNA extracted from the tissues. In our study, we found that glioma tissues preserved in liquid nitrogen $\left(-196^{\circ} \mathrm{C}\right)$ could well maintain RNA quality for at least 5 years. There are also other studies showed similar results such as Hebel et al.(2013)detected RIN values in blood samples stored at $-80^{\circ} \mathrm{C}$ for $4-19$ years and at $-196^{\circ} \mathrm{C}$ for $11-19$ years and found no adversely correlation between RNA quality and storage duration.DNA and protein are more stable than RNA. QPCR reactions of genomic housekeeping genes (GAPDH, ACTB) showed no signs of DNA degradation as the ct values were stable (ACTB: $22.63 \pm 0.63 \cdots 23.06 \pm 0.57$; GAPDH: $32.77 \pm 0.63 \cdots 33.32 \pm 1.50$ ). $\beta$-Globin PCR amplification showed that $100 \%$ of extracted DNA samples were of good quality with at least three amplified $\beta$-globin bands of increasing size.

207 According to our research, storage conditions of our biobank are suitable for long-term (at least 2085 years) sample preservation with high moleculer quality. However, there are also limitations of 209 our research. Heterogeneity has been found in various human tumors and glioblastoma (GBM) is 210 a highly heterogeneous tumor (Diaz-Cano,2012; Furnari et al.,2015). In our research, we only 
211 studied the tumor nuclei and necrosis proportion, but we did not study whether the pathological

212 type of samples preserved in our biobank is consistent with the previous pathological diagnosis.

213 We only studied gliomas and are not sure whether the other tumors have similar quality results.

214 Moreover, our biobank established only for a short period (presently up to 6 years), we should

215 further verify the quality over time to find optimal storage periods.

\section{Conclusion}

217 Storage conditions of our biobank are suitable for long-term (at least 5 years) sample 218 preservation with high molecular quality.

\section{Acknowledgements}

220 The authors kindly thank staffs of the Neurosurgical department of Beijing Tiantan Hospital in 221 helping with the collection of tissue samples.

\section{Citations:}

223 [1]Agnihotri S, Burrell KE, Wolf A, Jalali S , Hawkins C, Rutka JT, Zadeh G. 2013. 224 Glioblastoma, a brief review of history, molecular genetics, animal models and novel therapeutic 225 strategies.Arch Immunol Ther Exp(Warsz)61(1):25-41.

226 [2]Wilson TA, Karajannis MA, Harter DH. 2014. Glioblastoma multiforme: State of the art and 227 future therapeutics. Surgical Neurology Internationa15:64.

228 [3]Aldape K, Zadeh G, Mansouri S, Reifenberger G, von Deimling A.2015.Glioblastoma: 229 pathology, molecular mechanisms and markers. Acta Neuropathol129 (6):829-48.

230 [4] Ostrom QT, Bauchet L, Davis FG, Deltour I, Fisher JL, Langer CE, Pekmezci M, 231 Schwartzbaum JA, Turner MC, Walsh KM, Wrensch MR, Barnholtz-Sloan JS.2014.The 232 epidemiology of glioma in adults: a "state of the science" review. Neuro-Oncology16(7):896-913. 233 [5]Bryukhovetskiy I, Manzhulo I, Mischenko P, Milkina E, Dyuizen I, Bryukhovetskiy A, 234 Khotimchenko Y.2016.Cancer stem cells and microglia in the processes of glioblastoma 235 multiforme invasive growth. Oncology Letters12(3):1721-1728.

236 [6]Watson RWG, Kay EW, Smith D. 2010..Integrating biobanks: addressing the practical and 237 ethical issues to deliver a valuable tool for cancer research. Nat Rev Cancer10: 646-51. 
238 [7]Kang B, Park J, Cho S, Lee M, Kim N, Min H, Lee S, Park O, Han B. 2013.Current Status,

239 Challenges, Policies, and Bioethics of Biobanks.Genomics Inform11 (4):211-217.

240 [8]Tonje HH, Siver AM, Riyas V, Sitter B, Lamichhane S, Segura R, Giskeødegård GF, Bathen

241 TF. 2016.Impact of Freezing Delay Time on Tissue Samples for Metabolomic Studies. Front

242 Oncol6: 17.

243 [9]Iigen P, Stoldt S, Conradi L-C, Wurm CA, Rüschoff J, Ghadimi M, Liersch T, Jakobs S.

244 2014.STED Super-Resolution Microscopy of Clinical Paraffin-Embedded Human Rectal Cancer

245 Tissue. PLoS ONE9(7):e101563.

246 [10]Sanabria NM, Vetten M, Andraos C, Boodhia K, Gulumian M. 2014.Gold Nanoparticle

247 Interference Study during the Isolation, Quantification, Purity and Integrity Analysis of

248 RNA. PLoS ONE9(12):e114123.

249 [11]Griffin M, Abu-El-Haija M, Abu-El-Haija M, Rokhlina T, Uc A. 2012. A simplified and

250 versatile method for obtaining high quality RNA from pancreas. BioTechniques52(5):332-334.

251 [12]Kap M, Oomen M, Arshad S, Riegman P.2014. Fit for purpose frozen tissue collections by

252 RNA integrity number-based quality control assurance at the Erasmus MC tissue bank.

253 Biopreserv Biobank12 (2):81-90.

254 [13]Le Page C, Kobel M, de Ladurantaye M, Rahimi K, Madore J, Babinszky S, Bachvarov DR,

255 Bachvarova M, Beauchamp MC, Cass CE, Chadwick D, Colleen C, Damaraju S, Dufour J,

256 Gotlieb WH, Kalloqer SE, Portelance L, McAlipine JN, Matte I, Piche A, Shaw P, Roehrl MH,

257 Vanderhyden BC, Watson PH, Huntsman DG, Provencher DM, MesMasson AM. 2013.

258 Biopreserv Biobank11(2):83-93.

259 [14]Hewitt RE. 2011. Biobanking: The foundation of personalized medicine. Curr Opin

260 Oncol23:112-119.

261 [15]Olivieri EH, Franco LA, Pereira RG, Mota LD, Campos AH, Carraro DM.2014.Biobanking

262 practice: RNA storage at low concentration affects integrity. Biopreserv Biobank12(1):46-52.

263 [16]Zhang G, Xia B, Liu T, Zhang J, Niu M, Xu S, Bai X, You Z, Xu Q, Zhang Y, Cleveland J, 264 Zhang D, Pang D.2016. A High-Quality Biobank Supports Breast Cancer Research in Harbin, 265 China. Biopreserv Biobank14 (5):375-382. 
266 [17]Riemer AB, Keskin DB, Reinherz EL. 2012.Identification and validation of reference genes

267 for expression studies in human keratinocyte cell lines treated with and without interferon- $\gamma-\mathrm{a}$

268 method for qRT-PCR reference gene determination. Experimental dermatology21(8):625-629.

269 [18]Andreasson A, Kiss NB, Juhlin CC, Hoog A. 2013. Long-term storage of endocrine tissues at $270-80^{\circ} \mathrm{C}$ does not adversely affect RNA quality or overall histomorphology. Biopreserv

271 Biobank11:366-70.

272 [19]Hebels DG, Georgiadis P, Keun HC, Athersuch TJ, Vineis P, Vermeulen R, Portengen L, 273 Bergdahl IA, Hallmans G, Palli D, Bendinelli B, Krogh V, Tumino R, Sacerdote C, Panico S, 274 Kleinjans JC, de Kok TM, Smith MT, Kyrtopoulos SA. 2013. Performance in omics analyses of 275 blood samples in long-term storage: opportunities for the exploitation of existing biobanks in 276 environmental health research. Environ Health Perspect121:480-7.

277 [20]Diaz-Cano SJ.2012.Tumor Heterogeneity: Mechanisms and Bases for a Reliable Application 278 of Molecular Marker Design. International Journal of Molecular Sciences13(2):1951-2011. 279 [21]Furnari FB, Cloughesy TF, Cavenee WK, Mischel PS. 2015.Heterogeneity of epidermal 280 growth factor receptor signalling networks in glioblastoma. Nature reviews Cancer15(5):302-310. 
Table $\mathbf{1}$ (on next page)

Primers used for $\beta$-globin gene amplification by PCR 


\begin{tabular}{lllc}
\hline Amplicon & \multicolumn{1}{c}{ Forward primer } & \multicolumn{1}{c}{ Reverse primer } & $\begin{array}{c}\text { Size } \\
(\mathrm{bp})\end{array}$ \\
\hline I & GAAGAGCCAAGGACAGGTAC & CAACTTCATCCACGTTCACC & 268 \\
II & GCTCACTCAGTGTGGCAAAG & GGTTGGCCAATCTACTCCCA & 536 \\
& & GG & \\
III & ATTTTCCCACCCTTAGGCTG & TGGTAGCTGGATTGTAGCTG & 989 \\
IV & GGTTGGCCAATCTACTCCCAGG & TGGTAGCTGGATTGTAGCTG & 1327 \\
\hline
\end{tabular}


Table 2 (on next page)

Gene expression levels under different storage durations 


\begin{tabular}{|c|c|c|c|c|}
\hline \multirow[t]{2}{*}{ Year } & \multirow[t]{2}{*}{ gene } & \multicolumn{3}{|c|}{ Ct values (Average $\pm \mathrm{SD}$ ) of samples with } \\
\hline & & $\mathrm{RIN}<5$ & $5 \leq \mathrm{RIN}<6$ & $\mathrm{RIN} \geq 6$ \\
\hline \multirow[t]{2}{*}{2011} & ACTB & $16.17 \pm 0.14$ & & $14.50 \pm 0.41$ \\
\hline & GAPDH & $23.21 \pm 0.28$ & & $21.13 \pm 0.85$ \\
\hline \multirow[t]{2}{*}{2012} & ACTB & $18.26 \pm 0.00$ & & $14.39 \pm 0.66$ \\
\hline & GAPDH & $26.10 \pm 0.00$ & & $21.69 \pm 1.00$ \\
\hline \multirow[t]{2}{*}{2013} & ACTB & $15.79 \pm 0.00$ & $15.11 \pm 0$ & $14.40 \pm 0.58$ \\
\hline & GAPDH & $23.24 \pm 0.00$ & $22.10 \pm 0$ & $21.11 \pm 0.75$ \\
\hline \multirow[t]{2}{*}{2014} & ACTB & & & $14.70 \pm 0.65$ \\
\hline & GAPDH & & & $22.17 \pm 1.01$ \\
\hline \multirow[t]{2}{*}{2015} & ACTB & & & $14.32 \pm 0.47$ \\
\hline & GAPDH & & & $21.62 \pm 0.66$ \\
\hline
\end{tabular}




\section{Table 3 (on next page)}

Number of samples with ß-globin bands amplified of each year 


\begin{tabular}{cccccc}
\hline Primer & \multicolumn{5}{c}{ Number of samples of different storage periods } \\
& 2011 & 2012 & 2013 & 2014 & 2015 \\
\cline { 2 - 5 } I & 20 & 20 & 20 & 20 & 20 \\
II & 20 & 20 & 20 & 20 & 20 \\
III & 20 & 20 & 20 & 20 & 20 \\
IV & 15 & 13 & 16 & 19 & 15 \\
\hline
\end{tabular}


Figure 1

Constituent ratio of glioma subtypes

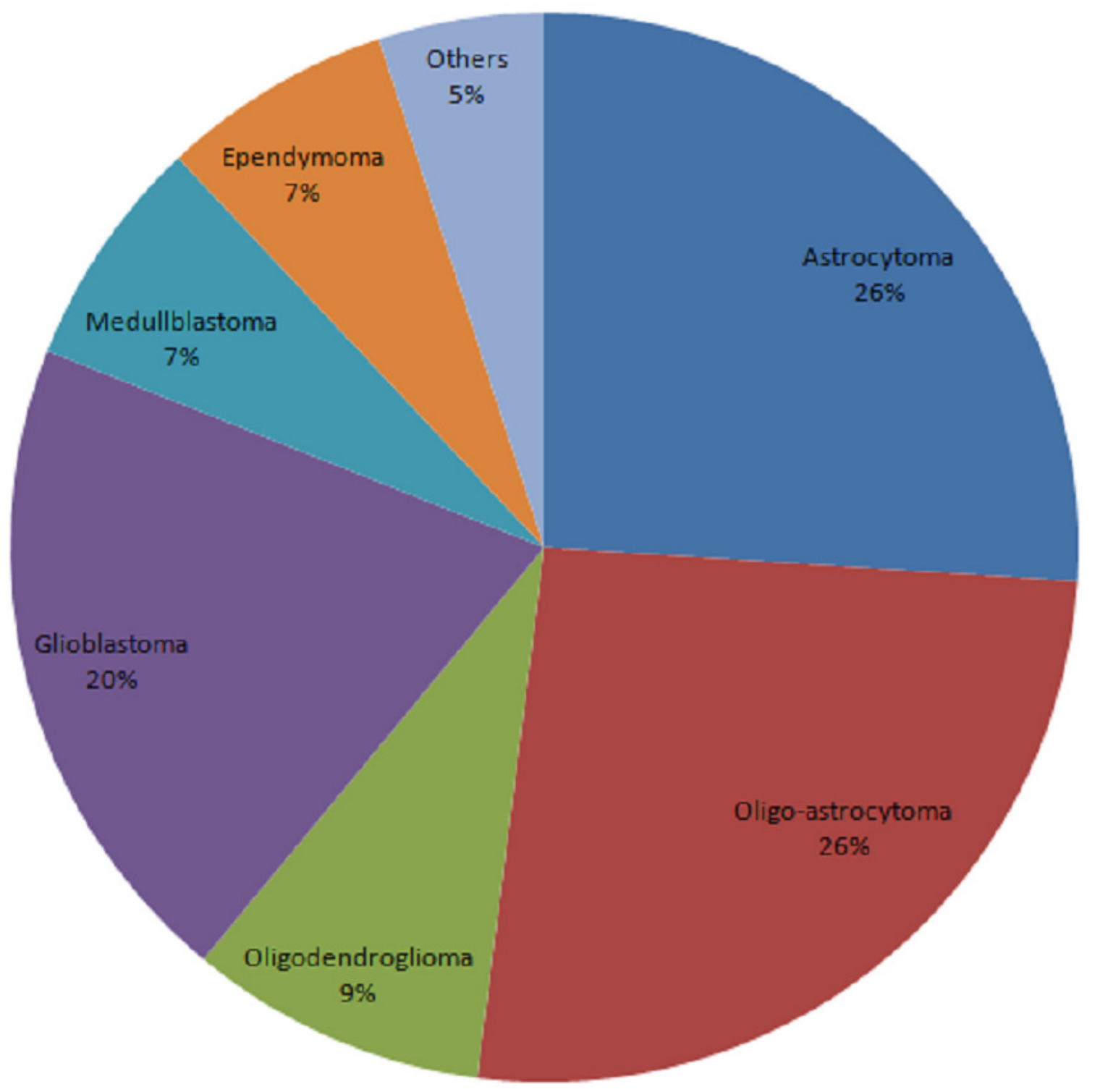




\section{Figure 2}

Morphology of glioma tissues preserved in liquid nitrogen of different storage periods (from 2011 to 2015)

(A) Morphology of glioma tissues preserved in liquid nitrogen in 2011. (B) Morphology of glioma tissues preserved in liquid nitrogen in 2012. (C) Morphology of glioma tissues preserved in liquid nitrogen in 2013. (D) Morphology of glioma tissues preserved in liquid nitrogen in 2014. (E) Morphology of glioma tissues preserved in liquid nitrogen in 2015.

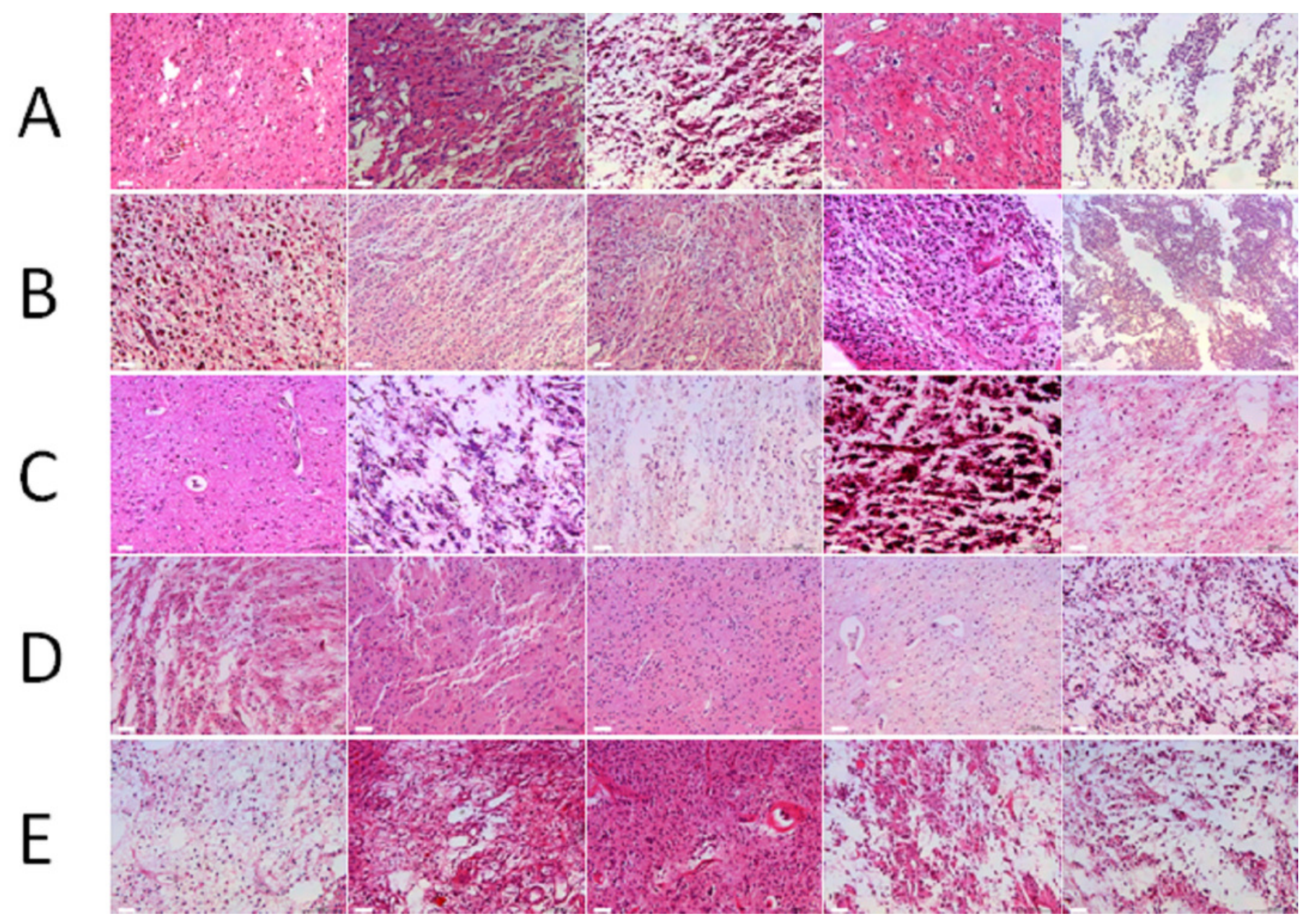


Figure 3

Ratio $260 / 280$ of RNA samples

\section{RNA}

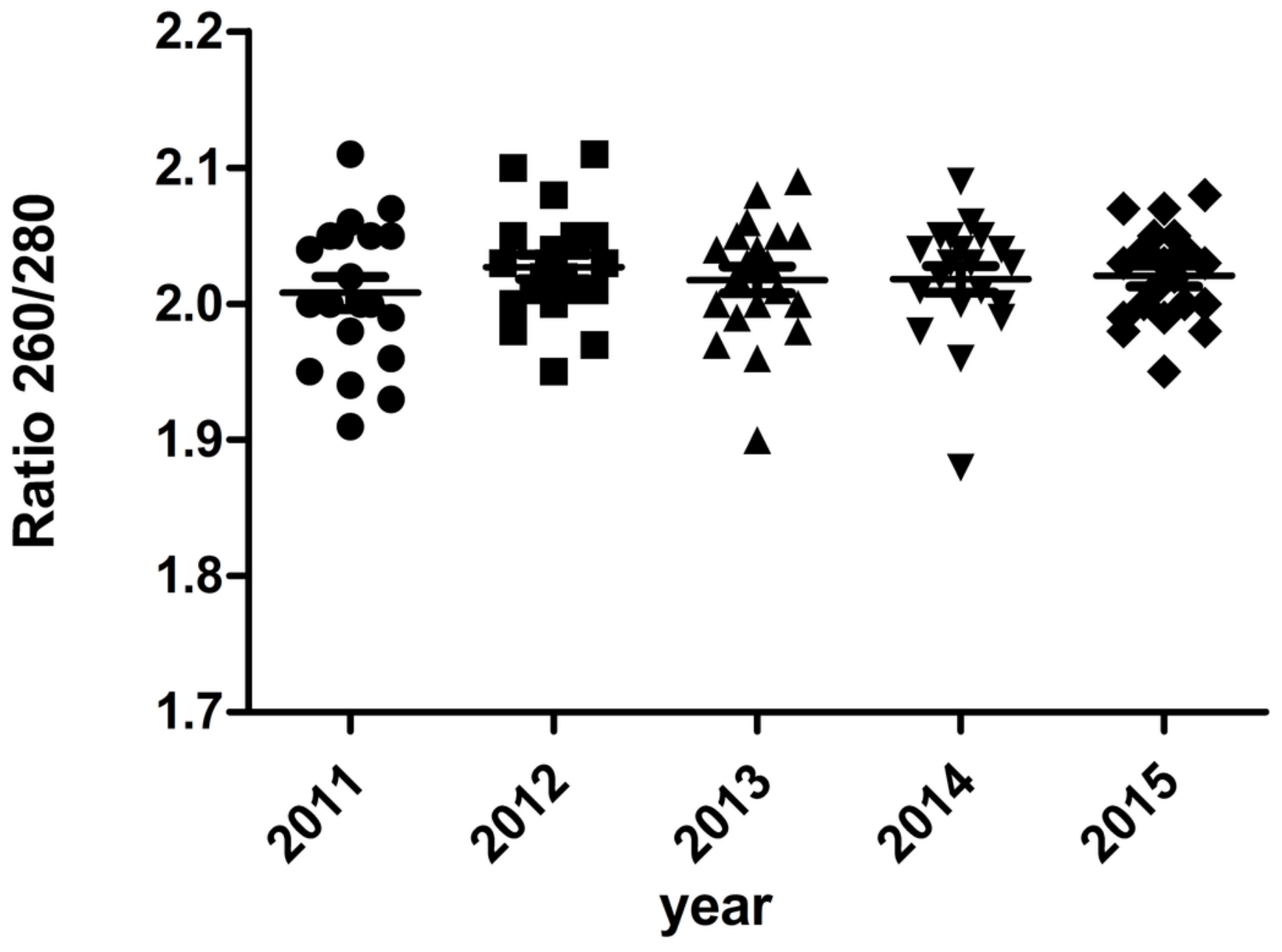


Figure 4

RNA integrity number of selected samples of different storage periods

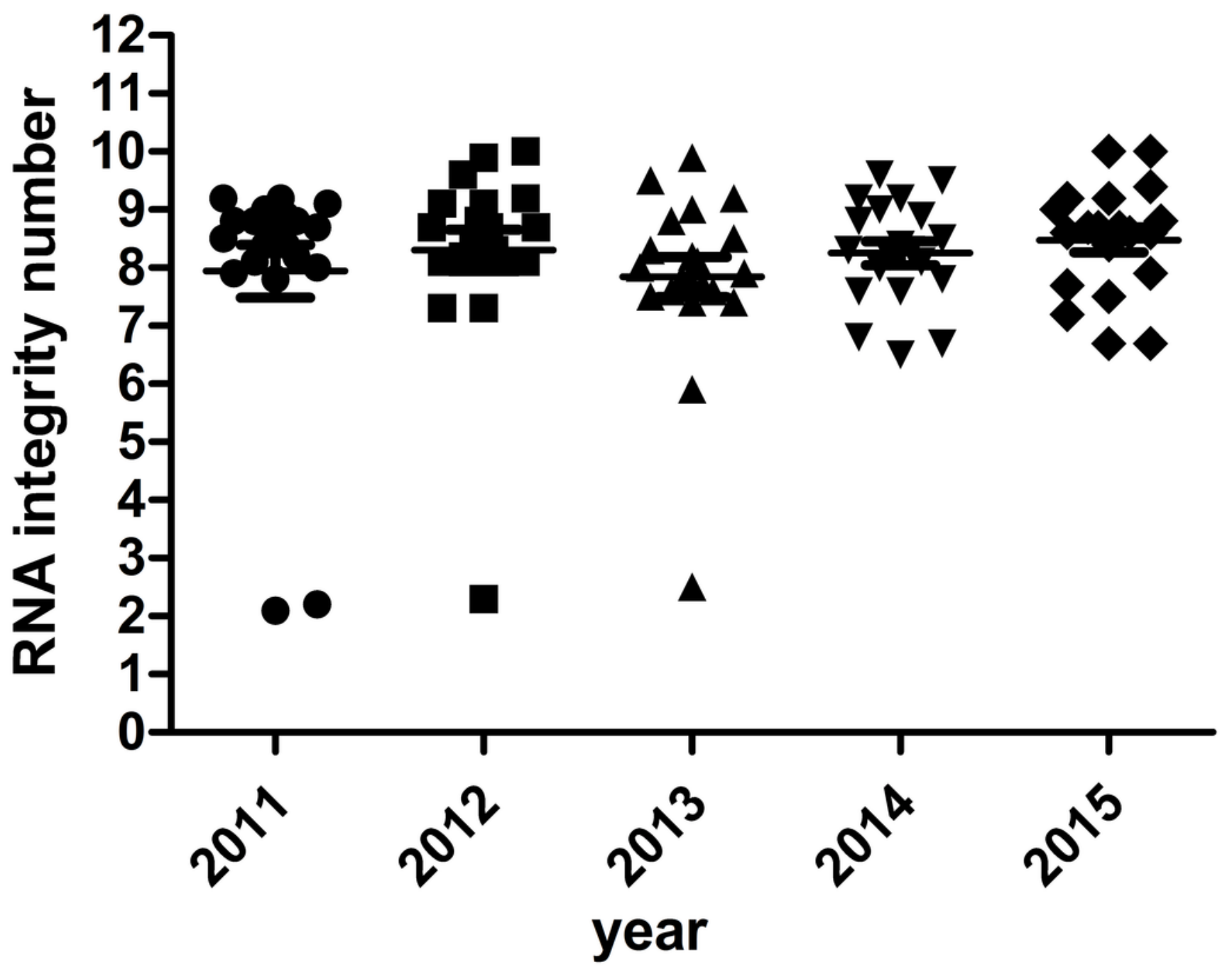


Figure 5

Gene expression levels under different storage durations

(A) Gene expression levels of ACTB; (B) Gene expression levels of GAPDH.

A B

ACTB

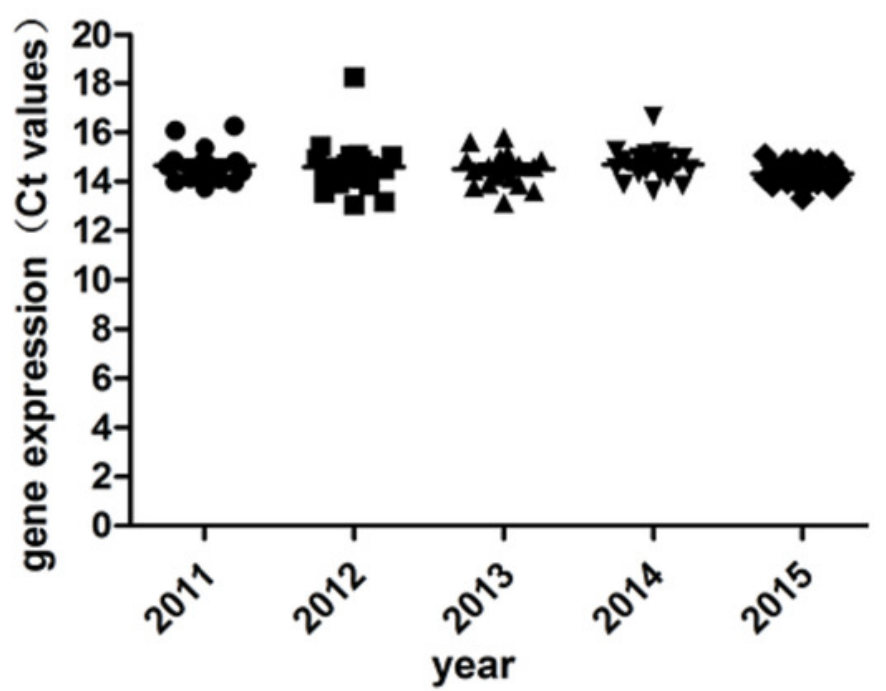

GAPDH

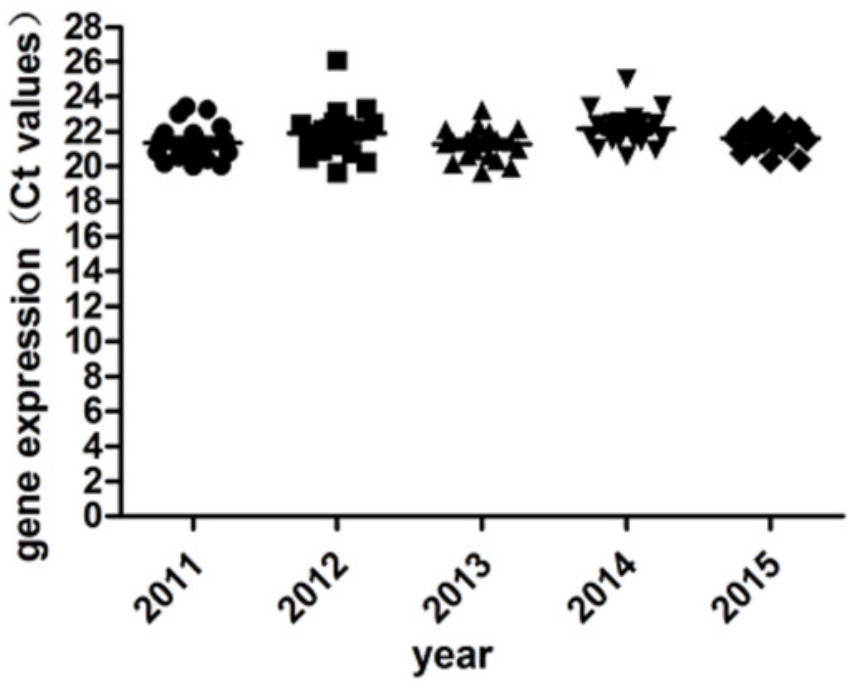


Figure 6

Ratio $260 / 280$ of DNA samples

\section{DNA}

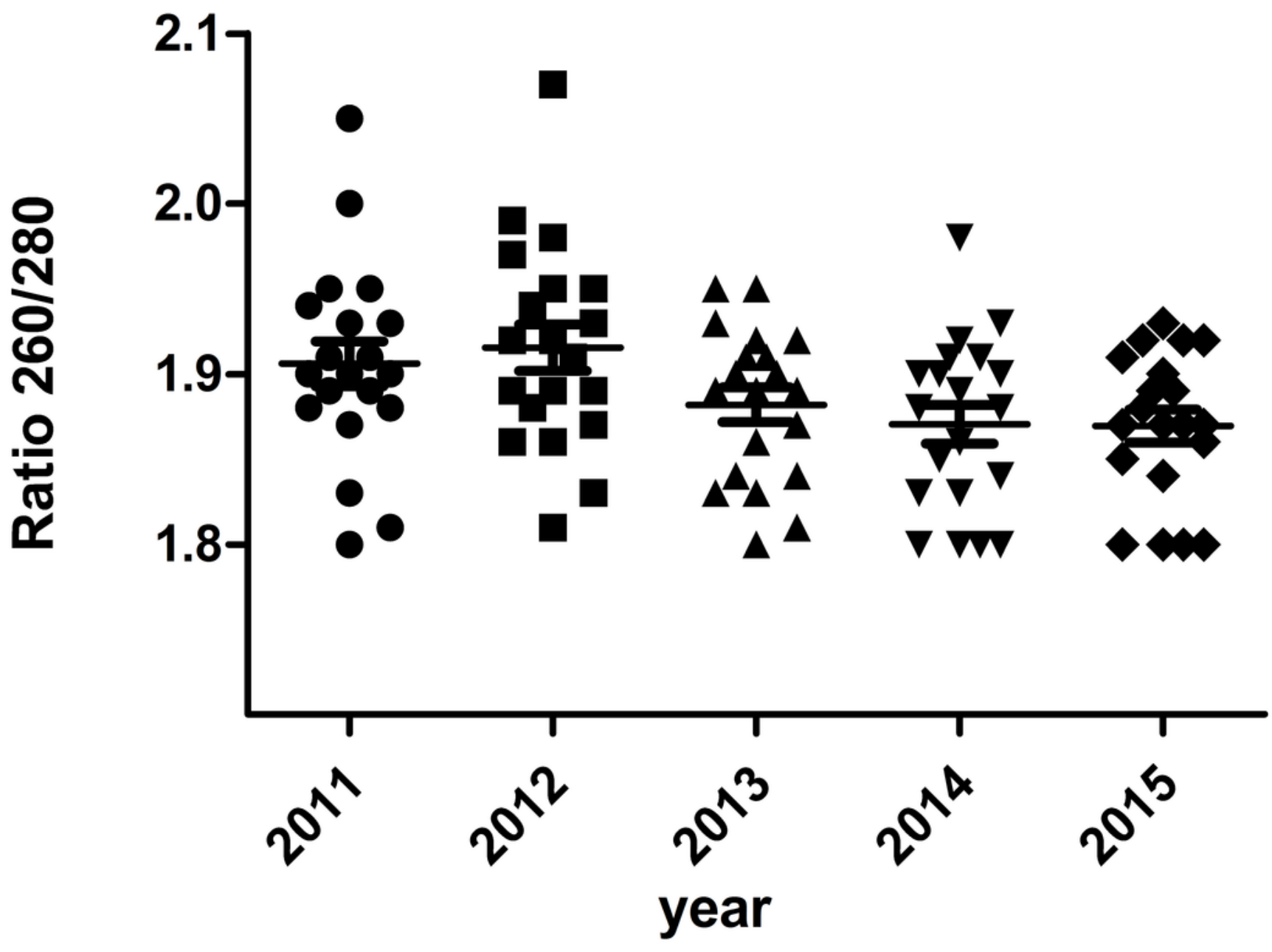


Figure 7

Ct values of genomic housekeeping genes under different storage durations

(A)Ct values of ACTB.(B)Ct values of GAPDH.

A

ACTB

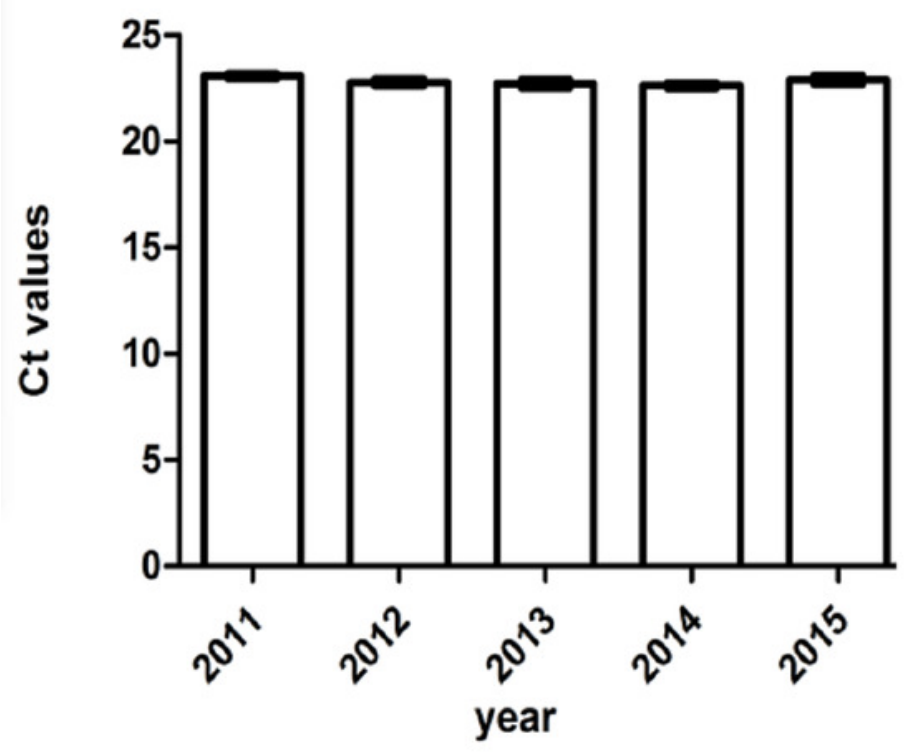

B

GAPDH

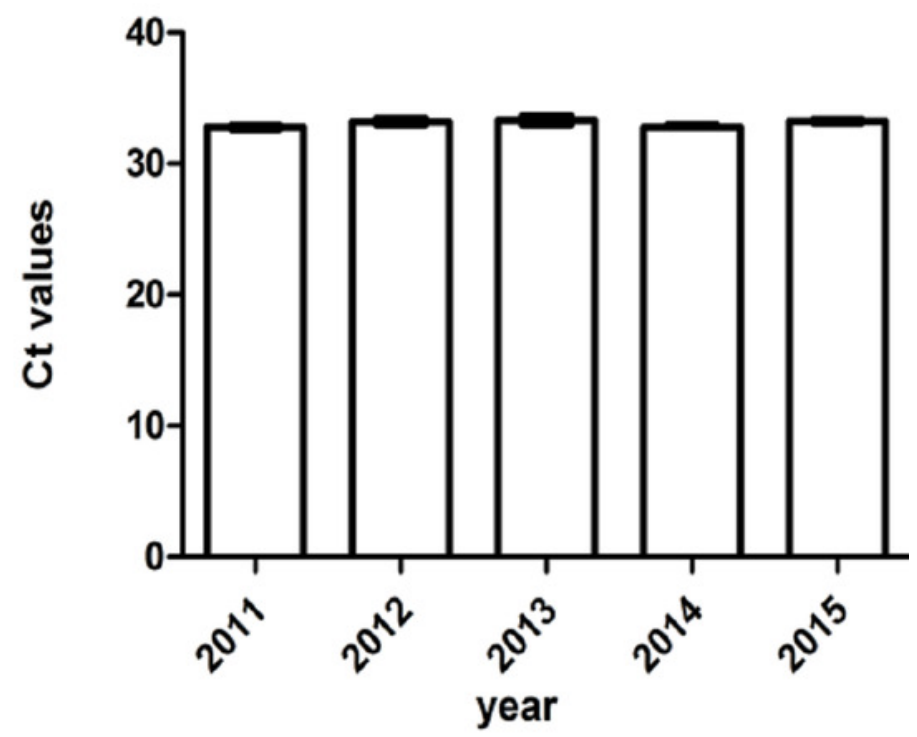

